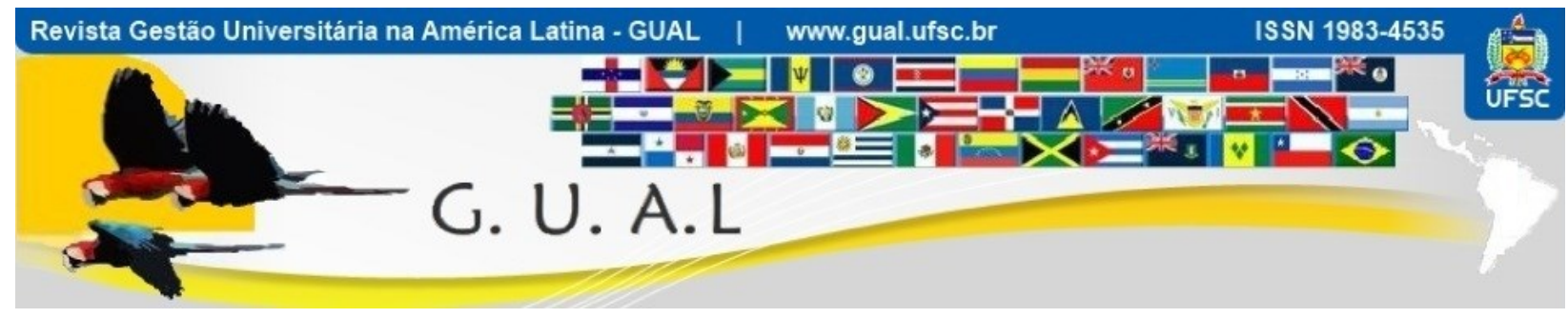

DOI: http://dx.doi.org/10.5007/1983-4535.2019v12n2p94

\title{
A INTERNACIONALIZAÇÃO DOS PROCESSOS DE COMPRAS EM IES COMUNITÁRIAS
}

\section{THE INTERNATIONALIZATION OF PURCHASING PROCESSES IN HEIS}

\author{
Julia Lautert, Bacharel \\ https://orcid.org/0000-0002-5940-9092 \\ jlauter1@ucs.br \\ Universidade de Caxias do Sul | Setor de Compras \\ Caxias do Sul | Rio Grande do Sul | Brasil \\ Roberto Birch Gonçalves, Doutor \\ http://orcid.org/0000-0002-6451-9034 \\ rbgoncal@ucs.br \\ Universidade de Caxias do Sul | Programa de Pós-Graduação em Biotecnologia \\ Caxias do Sul | Rio Grande do Sul | Brasil
}

Recebido em 10/abril/2017

Aprovado em 18/dezembro/2018

Publicado em 02/maio/2019

Sistema de Avaliação: Double Blind Review 


\begin{abstract}
RESUMO
As Instituições de Ensino Superior Comunitária (IES) são instituições sem fins lucrativos que desenvolvem ações essencialmente educacionais (ensino, pesquisa e extensão). Tem forte presença na vida da sociedade, atuando na área da pesquisa e promovendo o desenvolvimento. No exercício de suas atividades, por vezes, necessita adquirir materiais ou equipamentos oriundos de fora do país a cargo das IES, centralizando estas ações no setor de suprimentos ou compras. O objetivo do artigo é identificar e analisar as características dos processos de compras internacionais nas IES Comunitárias. Os procedimentos metodologicos aplicados nesse estudo foram através de uma pesquisa exploratória, com abordagem qualitativa de estudo de caso. A coleta de dados foi realizada por meio de entrevistas presenciais e individuais em profundidade apoiadas por um roteiro semiestruturado. Os resultados mostram as dificuldades da IES na gestão cotidiana, principalmente por conta da intensidade e diversidade das operações e a inabilidade na utilização do sistema informatizado. No aspecto da importação a dificuldade refere-se aos processos serem de alto valor, únicos e com muitas especificidades, além das dificuldades provenientes das imperfeições das solicitações de compras dos demandantes.
\end{abstract}

Palavras-chave: Instituição de Ensino Superior Comunitária. Compras Internacionais. Importação.

\begin{abstract}
Community Higher Education Institutions (HEICs) are non-profit institutions that carry out essentially educational activities (teaching, research and extension). They have a strong presence in society, working in the research and promoting development. In the exercise of its activities, sometimes, it needs to acquire foreign materials or equipments of load of the HEI, centralizing these actions in the sector of supplies or purchases. The aims of the study are to identify and analyze the characteristics of the purchasing process in the Community HEIs. The methodological procedures applied to this study were carried out through an exploratory research, with a qualitative approach to the case study. A data collection was performed by a means of face-to-face interviews and individuals in-depth supported by a semi-structured script. The results show difficulties of the HEI in day-to-day management mainly due to the intensity and diversity of operations and the ability to use the computerized system. Regarding importation the difficulty is related to the high value processes, unique and with many specificities, besides the difficulties arising from the imperfections of the applicants' purchase requests.
\end{abstract}

Keywords: Community Higher Education Institutions. International Purchasing. Import. 


\section{INTRODUÇÃO}

A educação superior brasileira está dividida em Instituições Públicas, Privadas e Comunitárias, cada qual com suas próprias características e experiências significativas para a educação brasileira. As Instituições de Ensino Superior (IES) Comunitárias, também chamadas de Universidades Comunitárias (UCs) é o foco principal desse trabalho, pois é um assunto que polariza, ou afeta, um segmento substancial da sociedade (MARTINS, 2012). Foram criadas pela sociedade civil, possuem gestão democrática e participativa a favor da inclusão social e do desenvolvimento regional com importância relevante para as comunidades que elas pertencem (SCHMIDT, 2009).

As Universidades Comunitárias ofertam cursos de licenciatura, bacharelado e pósgraduação. Participam de programas de financiamento governamentais como o Programa de Financiamento Estudantil (FIES), possuem programas de bolsas de estudo próprias ou de outros convênios além de possuírem projetos de pesquisa e extensão. Os projetos de pesquisas são importantes para fomentar o desenvolvimento e crescimento científico regional. A pesquisa é um dos principais pilares que fundamenta e diferencia a atuação de uma universidade. É dela que se originam novos conhecimentos e ideias, que podem ser transformados em produtos, processos e tecnologias, bens culturais e práticas inovadoras, que, por sua vez, irão gerar o desenvolvimento e o bem-estar para a sociedade (UCS, 2016). No entanto, a inovação e o crescimento científico dependem, por vezes, de produtos ou serviços adquiridos no exterior, fato não tão corriqueiro para as IES.

Diante do exposto, a proposta desse estudo é analisar os processos e as estratégias de compras das IES Comunitárias, especialmente no que diz respeito às importações de bens e serviços, devido a suas dificuldades e características particulares.

O estudo se justifica, pois o Brasil possui 7.305.977 de alunos matriculados no ensino superior, sendo 5.373.450 (aproximadamente 71,4\%) na rede privada e 1.932 .527 em rede pública (IBGE, 2016; INEP, 2013). Dessa distribuição, são 66 IES Comunitárias e 16 delas estão no Estado do Rio Grande do Sul, sendo 15 filiadas ao COMUNG (Consórcio das Universidades Comunitárias Gaúchas), entidade que as representa. Juntas reúnem cerca de 180.000 alunos em mais de 40 campis universitários, distribuídos em mais de 380 municípios, correspondendo o maior sistema de educação superior do Estado (COMUNG, 2016).

O motivo de escolher as Universidades Comunitárias é devido a sua contribuição para o desenvolvimento social e regional, que desde sua criação foram motivadas pelas 
comunidades locais no interesse de acesso à educação superior que estava concentrado nas grandes capitais.

Para a realização do estudo optou-se por uma abordagem qualitativa utilizando-se como ferramenta metodológica o estudo de caso. A análise deu-se sobre uma IES comunitária localizada na serra gaúcha com intensa regionalização e reconhecida com um exemplo de atuação comunitária.

Os resultados mostram as dificuldades do setor de compras da IES em manter o alinhamento entre o estratégico e o operacional por conta da intensidade e diversidade das operações cotidianas, além de problemas na utilização de regras e procedimentos escritos e adequação ao sistema informatizado. Os objetivos principais do departamento estão relacionados a preço e prazo, mas também em tornar os processos claros e auditáveis devido a muitos projetos serem financiados por fontes externas. No ponto de vista da importação a dificuldade refere-se aos processos serem de alto valor, únicos e com muitas especificidades. A maior demanda por itens internacionais provem da pesquisa ou extensão e conta com o benefício da isenção de impostos devido ao caráter filantrópico da IES estudada.

\section{REFERENCIAL TEÓRICO}

Nesse capítulo são apresentadas referências teóricas no intuito de entender como as Universidades Comunitárias surgiram e como se constituem, além de discorrer sobre os seus processos de compras e de importação.

\subsection{A EDUCAÇÃO BRASILEIRA E AS IES}

Segundo Vannucchi (2011), a história da educação brasileira começa com a atuação de religiosos, sobretudo jesuítas, franciscanos, carmelitas, beneditinos e capuchinhos, entre os séculos XVI-XVII. Estes religiosos começaram a desenvolver um trabalho evangelizador, criando escolas confessionais, elementares de ler, escrever e contar, que não eram nem privadas e nem públicas, predominantemente doutrinadas pelos colonizadores. Após a proclamação da independência (1822), surgiu o decreto de D. Pedro I em 1827, criando o ensino elementar no Brasil. Um pouco antes disso, em 1824, graças à abertura dos portos em 1808 para as "nações amigas" e do processo imigratório, e bem mais tarde em 1875, surgiram nossas primeiras escolas comunitárias, com forte característica religiosa, mas ainda de grau elementar. 
Schmidt (2009) alega que o espírito comunitário, assim como a solidariedade e o comportamento cívico, são partes integrantes da própria história da colonização. O tipo de povoamento adotado juntamente com o cristianismo social desenvolvido, mais a experiência trazida pelos imigrantes que consequentemente foi posta em prática de maneira associativa, cooperativa ou até beneficente, podem ser considerados como os responsáveis pelos vínculos sociais intensos e consistentes que estabeleceram nas comunidades. A escola comunitária, fruto deste espírito comunitário, foi o embrião de uma série de Instituições Universitárias que surgiram no Brasil, posteriormente, conhecidas como IES Comunitárias.

As Instituições de Ensino Superior são modalidades de ensino que de acordo com sua organização acadêmica podem ser credenciadas como faculdades, centros universitários e universidades. Portanto, o funcionamento de Instituições de Educação Superior sem o devido ato de credenciamento/recredenciamento configura irregularidade administrativa, sem prejuízo dos efeitos da legislação civil e penal, de acordo com o Art. 11 do Decreto 5.773/2006 (MEC, 2016). O Brasil possui 2.391 Instituições de Ensino Superior, sendo que $87,4 \%$ do total das IES são Instituições Privadas. O restante, 12,6\%, refere-se às Instituições Públicas (INEP, 2013).

Segundo o Art. 20 da Lei 9.394, as Instituições de Ensino Privadas estão enquadradas em quatro categorias: i) particulares em sentido estrito, as que são instituídas e mantidas por uma ou mais pessoas físicas ou jurídicas de direito privado; ii) comunitárias, as que são instituídas por grupos de pessoas físicas ou por uma ou mais pessoas jurídicas, inclusive cooperativas de professores e alunos que incluam na sua entidade mantenedora, representantes da comunidade; iii) confessionais, as que são instituídas por grupos de pessoas físicas ou por uma ou mais pessoas jurídicas que atendem a orientação confessional e ideologia específica e ao disposto no inciso anterior; e, iv) filantrópicas, na forma da lei (BRASIL, 1996).

\subsection{A UNIVERSIDADE COMUNITÁRIA}

Na primeira metade do século XX, a complexidade crescente da vida social e econômica exigia além do desenvolvimento administrativo, comercial e bancário, o crescimento do setor educacional principalmente o que diz respeito a cursos superiores. As comunidades acabaram se organizando por si só e foram criando escolas de nível secundário gratuitas, munidas de esforços e mantidas por associações religiosas ou beneficentes locais. 
As sociedades sem o devido apoio do poder público se organizavam para a instalação de escolas superiores, mediante associações e fundações (VANNUCCHI, 2011).

Com a Reforma Universitária ocorrida em 1968, surge um sistema de ensino distinto, articulado entre o ensino e a pesquisa na autonomia acadêmica, estruturado nos moldes de empresas educacionais focadas no lucro e para um rápido atendimento das demandas, sem esquecer-se do compromisso com o interesse público (MARTINS, 2012). Devido ao incentivo público através da intensificação das políticas governamentais para a expansão do ensino superior, e devido à crise instalada nas Instituições Públicas forma-se o cenário para o surgimento das IES Comunitárias.

Porem, somente na década de 80 as Universidades Comunitárias se consolidam e passam a serem citadas nas reuniões do Conselho de Reitores das Universidades Brasileiras como Instituições Públicas não estatais. Em 1988 durante a elaboração da nova Constituição da República, se discutiu a destinação de verbas públicas federais para essas IES de caráter não empresarial, foi reconhecido o modelo comunitário. O artigo 213 da Constituição Federal de 1988 consagrou o status constitucional da Universidade Comunitária como instituição pública não estatal (VANNUCCHI, 2011). Com a expansão do ensino superior no Brasil, as Instituições Comunitárias passam a atuar em um campo que era dominado quase que exclusivamente pelo Estado. Por sua proximidade com as comunidades, essas IES atuam onde o governo e o mercado não atendiam plenamente, enfrentando questões que eram exclusivas do Estado como as ecológicas, direitos das minorias, desemprego, violência entre outros (SIEWERDT, 2011).

No Brasil são 2.391 IES, destas 195 são universidades e apenas 66 se declaram Comunitárias e são filiadas a ABRUC (Associação Brasileira das Universidades Comunitárias) (INEP, 2013; ABRUC, 2016). A ABRUC foi criada com a adesão de vinte e dois reitores no ano de 1995 em Brasília, como pessoa jurídica de direito privado, sem fins lucrativos na sede do Conselho de Reitores das Universidades Brasileiras, com o objetivo principal de buscar qualidade acadêmica e fortalecer os seus compromissos específicos de responsabilidade social (VANNUCCHI, 2011).

A ABRUC caracteriza as IES Comunitárias como "Instituições sem fins lucrativos, que desenvolvem ações essencialmente educacionais, como ensino, pesquisa e extensão, com notória excelência em suas atividades. A este cenário soma-se sua forte vocação social, com expressiva presença na área de saúde por profissionais altamente qualificados" (ABRUC, 2016). Schmidt (2009), explica que o significado de comunitário é aquilo que é comum à 
comunidade, o que é coletivo, o que é de todos os membros da comunidade. Não pertence ao Estado, nem a grupos particulares. É uma das formas de Instituições ou organizações públicas voltadas à coletividade, são Instituições sem fins lucrativos, com gestão democrática e participativa, autênticas Instituições Públicas não estatais em prol da inclusão social e do desenvolvimento do país (SCHMIDT, 2009).

Segundo Vannucchi (2011) para poder entender e explicar a identidade das Universidades Comunitárias no Brasil, não é suficiente indicar somente a sua causa, ou seja, o seu princípio constitutivo (comunidade acadêmica), matéria prima de toda e qualquer IES, mas sobretudo sua inserção regional. Schmidt (2009) argumenta que as Comunitárias possuem características inovadoras: seu patrimônio pertence a entidades da sociedade civil e/ou órgãos do poder público local; não têm fins lucrativos e os seus resultados econômicos são reinvestidos na própria Instituição, controlados pela mantenedora; há transparência administrativa, a prestação de contas é feita à sociedade e ao poder público; a gestão é democrática, já que há participação da sociedade nos órgãos deliberativos e ainda existe uma notória preocupação com a realidade e o desenvolvimento regional. No entanto, para que as IES comunitárias se desenvolvam e sejam competitivas, precisam aprimorar seus aspectos administrativos e processos internos. Nesse sentido o setor de compras da instituição desempenha papel fundamental para o crescimento da IES.

\subsection{COMPRAS}

De acordo com Araújo (1978) a lógica da boa compra é adquirir o material necessário, em tempo oportuno, em quantidades convenientes e pelo menor preço. É uma função ampla, que não é apenas de responsabilidade exclusiva do departamento de compras (ARNOLD, 1999). Os materiais adquiridos podem ser diretos, que irão ser utilizados operação da empresa, ou indiretos, que são para todo o restante da organização. Já os serviços contratados, podem ser relativos à manutenção, limpeza e vigilância ou serviços que a empresa terceiriza (não produz) por diagnosticar ser mais em conta (DIAS; COSTA, 2012).

Ammer (1979) afirma que a qualidade é o objetivo mais importante, pois não obtendo a qualidade necessária ao material, o comprador não adquire nada que possa valer à pena, pois preço, prazo de entrega ou boa relação com o fornecedor não irá suprir um material que não terá uso. Para Dias (2011) quatro são os objetivos básicos de um departamento de compras: i) obter um fluxo contínuo de suprimentos; ii) coordenar esse fluxo de maneira que seja aplicado um mínimo de investimento; iii) comprar materiais e insumos aos menores 
preços, obedecendo a padrões de quantidade e qualidade definidos; iv) procurar uma negociação justa e honrada as melhores condições para a empresa, principalmente em termos de pagamento.

Para que o fluxo seja continuo é necessário haver uma previsão de demanda e necessidades de suprimentos. Quando se estabelece quantidades com prazos suficientes para se operar uma boa compra, é possível que o comprador execute o seu trabalho com tempo necessário para negociar e receber os produtos de maneira satisfatória (DIAS, 2011). De fato, para Arnold (1999) o setor de compras tem como responsabilidade principal localizar fontes adequadas de suprimentos e de negociar bons preços. Portanto assegurar que e as matériasprimas, material de embalagem e peças exigidas pela produção estejam à disposição nas quantidades certas, no tempo certo, compradas dentro das especificações mínimas e com o menor preço, já que o custo ou a qualidade destes insumos é componente fundamental no custo final do produto (DIAS, 2011). Nesse sentido, Slack et al. (1997) complementam que a compra de materiais representa um custo de até $50 \%$ do da produção.

Dentro do setor de compras de uma universidade podem-se organizar as demandas e distribuí-las entre os compradores por meio de grupos. Esta organização é funcional quando as atividades têm tamanho moderado e são entregues a compradores individuais. Os itens de cada grupo são especificados de acordo com a origem, necessidade e valor do material. (DIAS, 2011). Baily e Farmer (2000) consideram que a divisão de trabalho por grupo de materiais corresponde à responsabilidade de um único comprador por uma faixa específica de itens, porem exige que o comprador possua conhecimentos técnicos, comerciais e de gerenciamento, com características típicas de um empreendedor (DIAS; COSTA, 2012, p.10).

No entanto, a intensividade e dinamismo das atividades cotidianas dos setores de compras das universidades geram inúmeras dificuldades. Os problemas mais comuns são as compras emergenciais, em razão de deficiências no planejamento da aquisição por parte dos solicitantes. Essas compras não possibilitam muitas alternativas aos compradores no que diz respeito à procura e negociação. Sem tempo suficiente, o comprador se vê obrigado muitas vezes a pagar mais caro, ou se depara com a carência do produto desejado, situações que repercutem na performance do setor de compras (DIAS; COSTA, 2012). Além disso, outros aspectos legais necessitam ser resolvidos. Em universidade é comum financiamentos de órgãos externos seja do governo ou não. Esse fato exige controles éticos e legais documentados e passíveis de serem auditados mostrando a lisura institucional no trato com valores financiados. 
Araújo (1978) acredita que o comprador não tem muita oportunidade para aprender algo sobre aquilo que está adquirindo. Falta tempo para aprofundar o conhecimento sobre os materiais que está comprando, não podendo avaliar o que foi cotado a preço mais alto se corresponde ou não ao seu real valor. Isso frequentemente ocorre devido ao acúmulo de atribuições, defronte com a dificuldade na obtenção de um determinado material, seja ele pela dificuldade na obtenção de matéria-prima, ou na localização de uma fonte de suprimento em condições de lhe fabricar os produtos solicitados. Outro ponto importante a ser lembrado é a dificuldade em conceber controle sobre aquilo que se compra, quem está pedindo e de que maneira solicita ao departamento de compras. A importância de tais controles se dá na revelação de procedimentos errados, que podem ser corrigidos considerando atingir benefícios para a própria organização (DIAS; COSTA, 2012).

Ainda o departamento de compras geralmente está ligado a quase todas as grandes decisões, incluindo planejamento, redução de custos, padronizações, entre outros. Ajudam no controle de estoques, comprando lotes mais econômicos, fazendo acordos especiais com os fornecedores a fim de reduzir estoques de segurança. Podem ajudar o departamento de vendas com programas de relações com fornecedores e alguns casos com indicações para vendas específicas (AMMER, 1979).

\section{METODOLOGIA}

Nesse estudo escolheu-se trabalhar com a pesquisa de caráter exploratório, pois é o tipo de pesquisa flexível que utiliza amostras não probabilísticas para a definição das informações que irão proporcionar uma aproximação à questão investigada (KÖCHE, 2007). É indicada nos casos de incerteza de acordo com os possíveis resultados que possam ser encontrados, pois avaliam a complexidade de determinado problema e a influência de suas variáveis (MALHOTRA, 2001), que é o caso desse estudo considerando o ambiente de uma Instituição comunitária que é pouco estudado.

Nesse contexto, optou-se pela realização de um estudo de caso numa Instituição de Ensino Superior Comunitária, localizada na região nordeste do Estado do Rio Grande do Sul, que atua em nove cidades, atingindo diretamente uma população de mais de 1 milhão de habitantes. Esta característica de unicidade conferiu à investigação os elementos de um "caso" de estudo. Assim, o fenômeno contemporâneo foi estudado dentro de um contexto real (a comunidade), no qual os limites entre o fenômeno e o contexto não estão claramente definidos respondendo as questões do tipo "como" e "por que" (YIN, 2010). 
A coleta de dados foi realizada por meio de entrevistas presenciais e individuais em profundidade que consistem numa investigação detalhada do entrevistado apoiadas por um roteiro semiestruturado. Adotou-se este formato atendendo a afirmação de Malhotra (2001) ao alegar que estas entrevistas podem revelar percepções mais profundas sobre motivações subjacentes já que atribuem as respostas diretamente ao entrevistado. A coleta de dados foi realizada durante os meses de agosto, setembro e outubro de 2016, com seis colaboradores da instituição estudada. Todas as entrevistas foram realizadas em local e horário definidos pelos entrevistados, pessoalmente e com a utilização de recurso de gravação. As entrevistas duraram em média 25 minutos, e posteriormente, foram transcritas integralmente para realização da análise, isso resultou em um volume de aproximadamente 10 páginas para cada entrevista respeitando fielmente as respostas dadas pelos respondentes.

Os dados da pesquisa foram analisados seguindo a técnica de análise de conteúdo por categorização que utiliza procedimentos sistemáticos e objetivos de descrição do conteúdo das mensagens proposta por Bardin (2004). As categorias que foram criadas considerando os assuntos estudados no referencial teórico são: identificação; compras; processo de compras e, processo de importação.

\section{ANÁLISE DOS DADOS E RESULTADOS}

Nessa seção são apresentadas a análise e a interpretação dos dados coletados levandose em consideração os perfis dos entrevistados e as demais categorias.

\subsection{PERFIL DOS RESPONDENTES}

O Quadro 1 mostra as principais informações do perfil dos respondentes. Nota-se que os respondentes possuem experiência, formação e são responsáveis pelos principais cargos do setor e possuem larga experiência na área, fatores que qualificam as respostas obtidas.

Quadro 1 Perfil dos respondentes

\begin{tabular}{|c|c|c|l|l|}
\hline Nome & Idade & Gênero & \multicolumn{1}{|c|}{ Formação } & \multicolumn{1}{|c|}{ Cargo/Função } \\
\hline E1 & 40 & M & Mestre em Administração de empresas & Gerente \\
\hline E2 & 40 & F & Formação em Administração Comércio Exterior & Compradora \\
\hline E3 & 29 & F & Superior incompleto & Compradora \\
\hline E4 & 44 & M & Formação em Economia & Ex-gestor \\
\hline E5 & 51 & M & Doutor em Engenharia Mecânica & Professor e Diretor \\
\hline E6 & 39 & M & Mestre em Biotecnologia & Técnico de Laboratório \\
\hline
\end{tabular}


Três entrevistas foram com colaboradores do setor de compras da IES Comunitária estudada. O primeiro entrevistado foi o gerente do setor, e os outros dois respondentes são compradores deste mesmo departamento. Na sequencia foram entrevistados dois colaboradores da mesma Instituição, porém que não atuam diretamente no setor de compras, mas que têm envolvimento indireto através de solicitações de compra internacionais, para serem captadas as percepções sobre o desempenho do setor. E para complementar, foram feitos alguns questionamentos a um ex-gestor desse mesmo setor detentor de larga experiência na área, mas principalmente devido a sua expertise em licitações internacionais.

\subsection{ANÁLISE DAS CATEGORIAS}

A análise e discussão dos resultados estão organizadas de acordo com as categorias estabelecidas: compras, processos de compras e processos de importação.

\subsubsection{Compras}

Esta categoria aglomera questões referentes ao setor de compras, uma visão sobre o seu objetivo, além de sua estrutura organizacional. A primeira questão proposta foi: "Como é a estrutura organizacional do setor de compras?" as respostas são apresentados no Quadro 2.

Quadro 2 Estrutura organizacional do setor de compras

\begin{tabular}{|c|c|c|}
\hline E1 & E2 & E3 \\
\hline $\begin{array}{l}\text { "[...] dividido por grupo de } \\
\text { produtos né, flexibilizada } \\
\text { conforme as demandas [...] } \\
\text { compartilha em mais de um o } \\
\text { conhecimento do processo e do } \\
\text { andamento das atividades }[\ldots] \text {... }\end{array}$ & $\begin{array}{l}\text { "Antes cada um tinha sua PASTA } \\
\text { específica de comprar. Então agora eu } \\
\text { observo que o E1 está mudando um } \\
\text { pouco a estrutura né, eu percebo que ele } \\
\text { tá começando a fazer uma espécie de } \\
\text { rodízio do que cada um compra [...]". }\end{array}$ & $\begin{array}{l}\text { "nós tínhamos uma divisão de } \\
\text { compras, cada um comprava seu } \\
\text { segmento, mas agora é mais } \\
\text { misturado tem dois compradores } \\
\text { para o mesmo produto, a linha } \\
\text { de produto [...]". }\end{array}$ \\
\hline
\end{tabular}

Observando o Quadro 2 nota-se uma convergência de opiniões, pois todos os entrevistados apontam o rodízio de compradores, como uma estratégia recente. E1 explica que o setor de importação faz parte do setor de compras que é composto também pelo setor de recebimento e almoxarifado. Estruturam o setor além de compradores, um gerente e uma pessoa que auxilia todo o setor e um coordenador de almoxarifado. Percebe-se que o setor está buscando um novo alinhamento operacional tendo mais do que uma pessoa em condições de realizar uma mesma função. Além disso, a atividade de importação divide espaço com as demais não tendo uma estrutura específica, principalmente devido ao fato de que, embora existam operações de alto valor, as importações não são corriqueiras na IES. 
A segunda questão da categoria "Compras" foi: "Quais são os objetivos principais do setor de compras?". O Quadro 3 mostra as respostas.

Quadro 3 Objetivos do setor de compras

\begin{tabular}{|c|c|c|}
\hline E1 & E2 & E3 \\
\hline $\begin{array}{l}\text { "É prover todos os serviços e materiais } \\
\text { ou produtos [...] de uma forma que a } \\
\text { gente consiga atender no prazo, } \\
\text { privilegiando a economicidade }[. . .] \\
\text { obrigatoriamente mantendo também um } \\
\text { processo [...] auditável [...]". }\end{array}$ & $\begin{array}{l}\text { "Uma compra consciente }[\ldots] \\
\text { devemos sempre observar o preço em } \\
\text { primeiro lugar }[\ldots] \text { mas em algum } \\
\text { caso tem que ter bom senso }[\ldots] \\
\text { analisar preço, qualidade e entrega } \\
{[\ldots] \text {... }}\end{array}$ & $\begin{array}{l}\text { "Comprar corretamente. } \\
\text { A gente analisa os } \\
\text { preços, compra-se com o } \\
\text { menor preço, mas } \\
\text { também visando a } \\
\text { qualidade". }\end{array}$ \\
\hline
\end{tabular}

Pode-se perceber que há unanimidade nas respostas no que se refere à compra econômica ou de menor preço. E3 assinala: “[...] compra-se com o menor preço [...]” o que o E1 sempre me passou é que nós devemos sempre observar o preço em primeiro lugar [...]”, a orientação gerencial é procurar o menor preço sempre. De fato, o preço é o objetivo principal do setor de compras (DIAS; COSTA, 2012) e se confirma no caso. No entanto, para a IES, outro ponto importante mencionado por E1, essa característica também é de preocupação de E2 "analisar preço, qualidade e entrega". Vale salientar que E1 abordou com ênfase que é preciso deixar o processo claro e auditável, fato que não foi mencionado por E2 e nem E3.

A terceira questão da categoria Compras (Quadro 4) está relacionada com a importância do setor: "Como você classifica a importância do setor de compras em sua IES?".

Quadro 4 Importância do setor de compras

\begin{tabular}{|l|l|l|}
\hline \multicolumn{1}{|c|}{ E1 } & \multicolumn{1}{|c|}{ E2 } & \multicolumn{1}{c|}{ E3 } \\
\hline $\begin{array}{l}\text { "É importante pela característica que é de "Ai eu classifico como } \\
\text { fornecer para todos os demais né ". }\end{array}$ & $\begin{array}{l}\text { "eu creio que o setor de compras é } \\
\text { muito, como altíssima ". } \\
\text { um setor estratégico ". }\end{array}$ \\
\hline
\end{tabular}

Os entrevistados concordam que o setor de compras é fundamental para a organização (DIAS; COSTA, 2012), pois além de abastecer as necessidades da organização, garantindo o seu funcionamento, pode trazer mais benefícios como economia, lucratividade e otimização de recursos.

\subsubsection{Processo de compras}

A primeira pergunta dessa categoria foi relacionada com a gestão de demandas do setor: “Como chegam às demandas até o setor de compras?”. 
Para explicar a questão utilizou-se de exemplos citando a "requisição de materiais" que é a nomenclatura utilizada para nomear o formulário que registra a origem das aquisições do setor de compras (BAILY; FARMER, 2000; DIAS; COSTA, 2012) as quais normalmente são geradas por demandas externas ao setor, e são o ponto de partida para o processo de compras. Segundo E1, as demandas chegam até o setor a partir de uma solicitação de compras: "existem os casos em que as solicitações verbais acontecem, mas elas são direcionadas para que se encaminhem o processo formal que é a emissão da solicitação de compra, um formulário físico, papel ou eletrônico via sistema informatizado".

Para E2 e E3 existe apenas uma forma que chegam as demandas de aquisições para o setor: "hoje a gente utiliza um sistema de software chamado $\mathrm{OBC}$, então a partir do sistema chega pra nós [...] o solicitante entra no OBC, faz a sua demanda e aí chega pra gente”. E1 (gerente do setor) concorda reforçando que tudo deveria "chegar" por solicitação virtual. Está presente o conflito entre a modernização e melhora de controle através do sistema e o antigo modo manual e pessoalizado, que ainda faz parte do dia a dia do setor, provenientes de algumas áreas que menor fluxo e que ainda não fazem parte do sistema integrado.

A pergunta seguinte referiu-se ao sistema de informática. "Existe algum sistema utilizado que unifique as informações dos processos de compras?” (Quadro 5).

Quadro 5 Utilização de sistema nos processos de compras

\begin{tabular}{|c|c|c|}
\hline E1 & E2 & E3 \\
\hline $\begin{array}{l}\text { O sistema é onde são executados os processos de compras [...] } \\
\text { no papel a gente tem três grupos que ainda permanecem, por } \\
\text { razões distinta, executadas na forma antiga. São os grupos de } \\
\text { compras da área de extensão e da área de pós-graduação em } \\
\text { função de ainda não estarem integrados ao orçamentário. }\end{array}$ & $\begin{array}{l}\text { "[...] sistema que envolve } \\
\text { então o solicitante o } \\
\text { comprador e o recebedor que } \\
\text { é o que é a unidade receptora } \\
\text { que é o almoxarifado [...]". }\end{array}$ & $\begin{array}{l}\text { "Sistema } \\
\text { próprio de } \\
\text { compras [...]". }\end{array}$ \\
\hline
\end{tabular}

A IES possui um sistema de compras integrado que abrange além do setor de compras, o setor de recebimento, no qual os solicitantes têm acesso para emitir suas demandas de aquisições, podendo acompanhar em tempo real as solicitações. No entanto, as áreas de extensão e de pós-graduação ainda compram através de um processo antigo, não informatizado, principalmente na pós-graduação devido à complexidade e irregularidade das demandas (cursos previstos que não se concretizam, com valores previstos que se modificam).

$\mathrm{Na}$ questão seguinte foi perguntado aos respondentes sobre as dificuldades do setor. “Quais são as maiores dificuldades encontradas no processo de compras?”, Quadro 6. 
Quadro 6 Maiores dificuldades do setor de compras

\begin{tabular}{|c|c|c|}
\hline E1 & E2 & E3 \\
\hline $\begin{array}{l}\text { "[...] falta de conhecimento dos processos } \\
\text { pelo público externo ao setor }[\ldots] \text { dificuldades } \\
\text { na prestação de contas }[\ldots] \text { o atendimento } \\
\text { deveria ser mais rápido }[\ldots] \text { compradores não } \\
\text { dominarem } 100 \% \text { das opções do sistema }[\ldots] " \text {. }\end{array}$ & $\begin{array}{l}\text { "[...] são alguns pequenos detalhes } \\
\text { do OBC que eu acho que o deixa } \\
\text { um engessado [...] mas a gente já } \\
\text { tá se acostumando, a gente sabe } \\
\text { que é o rodízio profissional [...]". }\end{array}$ & $\begin{array}{l}\text { "[...] a nossa maior } \\
\text { dificuldade é realmente } \\
\text { saber o que o } \\
\text { solicitante o precisa } \\
{[\ldots] " .}\end{array}$ \\
\hline
\end{tabular}

A complexidade das demandas e às intensas atividades dos setores de compras afetam as rotinas diárias dos compradores impactando as demais áreas das organizações e intensificam os problemas (DIAS; COSTA, 2012). E1, como gestor, possui uma visão mais ampla deste tema e analisa as dificuldades do setor, classificando em internas e externas. Nas externas associa à insatisfação por parte dos outros setores da IES, causada pela falta de conhecimento dos processos gerando compras emergenciais, que são os problemas mais comuns do departamento de compras (DIAS; COSTA, 2012). Para E1 essa falta de conhecimento impossibilita aos compradores seguirem um padrão, acarretando compras mais caras ou de produtos errados devido à falta de tempo para aquisição.

Quanto às dificuldades proporcionadas no ambiente interno, E1 relata que "uma dificuldade é o fato dos compradores não dominarem $100 \%$ das facilidades que o sistema proporciona, pois foi implementado há um ano e meio com diferentes níveis de apropriação". E2 concorda relatando que as suas solicitações de compras "ficam escondidas" na sua tela. Já o entrevistado E3 não demorou a responder e foi bastante claro em sua resposta: "a nossa maior dificuldade é realmente saber o que o solicitante precisa”. As descrições dos itens são muito genéricas e o comprador precisa retornar a demanda até receber uma descrição clara.

A última pergunta realizada na categoria "Processos de compras" está relacionada à padronização dos processos do setor: "O setor adota manual de procedimentos e normas? Com que frequência é utilizado?", o Quadro 7 representa as respostas de cada entrevistado.

Quadro 7 Manual de procedimentos e normas

\begin{tabular}{|c|c|c|}
\hline E1 & E2 & E3 \\
\hline $\begin{array}{l}\text { "Tem um manual, uma normativa } \\
\text { institucional que tá desatualizada } \\
\text { em função da implantação do } \\
\text { sistema, [...] ele foi rascunhado no } \\
\text { passado já está desatualizado há } \\
\text { uma década [...]". }\end{array}$ & $\begin{array}{l}\text { “[...] eu desconheço que tenha em } \\
\text { compras tá. Então a única coisa foi } \\
\text { esse fluxograma né que na verdade } \\
\text { não chega a ser um manual né ele } \\
\text { é só uma ideia, uma informação de } \\
\text { como funciona no geral }[\ldots] \text {... }\end{array}$ & $\begin{array}{l}\text { "[...] a gente na verdade não tem. } \\
\text { Cada comprador enfim faz tem o } \\
\text { seu processo. Cada um faz [...] tem } \\
\text { um padrão de orientação, mas de } \\
\text { repente cada um vai se adaptando } \\
\text { de sua maneira }[\ldots . .] \text {.". }\end{array}$ \\
\hline
\end{tabular}


As vantagens em se utilizar um manual de procedimentos são: i) padronização das atividades, evitando ou diminuindo erros; ii) orientação de funcionários novos; iii) aprimoramento e melhora do desempenho das atividades cotidianas (DIAS; COSTA, 2012). Ficou claro que E2 e E3 desconhecem a existência do manual de procedimentos e normas do setor, mas E1 confirma a sua existência, porém entende que o mesmo está desatualizado perante os processos atuais. E1 alerta "então na prática hoje o manual é um documento esquecido, eu já pedi pra as pessoas onde que fica e ninguém sabe”. E3 relata que cada comprador é orientado a seguir procedimentos, mas que no meio do processo ele pode adaptar a sua realidade: "a gente é orientado a fazer dessa maneira né, tem um padrão de orientação, mas de repente cada um vai se adaptando [...]" "[...] a gente consulta onde a gente anota ou consulta diretamente a pessoa que solicitou, mas o processo mapeado a gente não tem”.

\subsubsection{Processo de importação}

Por fim levantaram-se as questões sobre "Processo de Importação". "Existe demanda para compra no mercado internacional? Elas são rotineiras ou são tratadas como exceção?" Quadro 8 mostra as respostas.

Quadro 8 Compras internacionais

\begin{tabular}{|c|c|c|c|}
\hline E1 & E2 & E3 & E4 \\
\hline $\begin{array}{l}\text { "[...] normalmente são } \\
\text { situações de compras } \\
\text { bem especiais, não são } \\
\text { de rotinas né }[\ldots] \text { ". }\end{array}$ & $\begin{array}{l}\text { "Não é uma coisa de } \\
\text { exceção, as compras } \\
\text { internacionais }[\ldots] \text { ". }\end{array}$ & $\begin{array}{l}\text { "Eu creio que tem mais } \\
\text { processos nacionais, } \\
\text { mais processos normais } \\
{[\ldots] " \text {. }}\end{array}$ & $\begin{array}{l}\text { "As importações são tratadas } \\
\text { como exceções e respeitam um } \\
\text { critério: a não existência de } \\
\text { similaridade no Brasil [...]". }\end{array}$ \\
\hline
\end{tabular}

Para o E1 as compras internacionais não são rotineiras, pois os maiores volumes de compras são no mercado nacional: "quando a gente tem produtor nacional que atenda não se vai para o mercado externo". E1 também salienta que a maioria das compras internacionais está associada à área de pesquisa da Instituição.

E1, E3 e E4 relatam que as compras internacionais são tratadas como exceção e que o maior volume de compras é no mercado nacional, diferentemente do entrevistado E2. Segundo E1, define-se que a partir do valor da compra ou do tipo de produto consulta-se o mercado internacional. Discordando de E1, a visão de E2 quanto ao mercado internacional e sua frequência é: "a gente na verdade não tem um método, alguma variável que diga só acima de tal preço vai ser pesquisada fora. A gente pesquisa qualquer coisa quando tem uma indicação do solicitante, independente de valores pesquisamos no mercado externo". E2 
aponta ainda que a tomada de decisão está associada à economicidade, e que geralmente inicia-se um processo de importação quando demandado pela à área de pesquisa. Já para o E4 “a não existência de similaridade no mercado nacional" era a prerrogativa fundamental para que a Instituição inicia-se um processo de importação. Alegou ainda que: "Independente de alguns equipamentos serem fabricados no Brasil, a diferenciação tecnológica entre produtos importados e nacionais, faziam com que os equipamentos importados fossem únicos e, portanto, sem similar nacional" (E4).

A segunda pergunta da categoria "Processos de Importação" foi: "Quais são os canais utilizados: importação direta (importação própria), importação indireta ou importação por encomenda (trade)?”.

Quadro 9 Canais de importação

\begin{tabular}{|c|c|}
\hline E1 & E3 \\
\hline $\begin{array}{l}\text { “[...] quem faz o grande trabalho de acompanhamento e desenvolvimento da } \\
\text { atividade de importação é um despachante que nos apóia }[\ldots] " .\end{array}$ & "Não, não sei”. \\
\hline
\end{tabular}

Esta pergunta apenas foi feita para os entrevistados mais envolvidos como o processo de importação (Quadro 9). E1 explicou que sua equipe conta com auxílio de um despachante para efetuar as importações, E3 alegou não saber detalhes sobre os canais.

Já na terceira pergunta foi questionado se existe incentivo fiscal nas importações da Instituição e como seria essa tributação: "Como é a tributação das mercadorias importadas? Existe algum tipo de incentivo fiscal?" apresentado no Quadro 10.

Quadro 10 Tributação x incentivos fiscais

\begin{tabular}{|c|c|c|c|}
\hline E1 & $\mathbf{E 2}$ & E3 & E4 \\
\hline $\begin{array}{l}\text { "Na verdade o que a gente } \\
\text { tem pelo fato de ser } \\
\text { filantrópico é isenção dos } \\
\text { impostos de importação e } \\
\text { também dos impostos } \\
\text { relacionados ao estado né". }\end{array}$ & $\begin{array}{l}\text { "[...] Instituição } \\
\text { Filantrópica de } \\
\text { Ensino é isenta de } \\
\text { impostos". }\end{array}$ & $\begin{array}{l}\text { "Não, sei } \\
\text { detalhes } \\
\text { disso". }\end{array}$ & $\begin{array}{l}\text { "[...] passamos a utilizar a Lei } 8.032 \text { de } 12 \\
\text { de abril de } 1990 \text {, que também trata da } \\
\text { isenção ou redução de impostos de } \\
\text { importação [...] estabelece o direito ao } \\
\text { benefício, para partidos e Instituições de } \\
\text { educação ou de assistência social [...]". }\end{array}$ \\
\hline
\end{tabular}

Conforme E1 e E2, por ser uma Instituição de Ensino Filantrópica a IEs estudada é isenta de impostas de importação e também dos impostos relacionados ao ICMS. O entrevistado E3 não trabalha diretamente nos processos de importação e por isso justifica não saber responder também a este questionamento. E4 salienta que a IES iniciou suas importações, utilizou por um período de mais ou menos 5 anos, exclusivamente a Lei 8.010, 
de 29 de março 1990. Esta Lei dispõe sobre importações de bens destinados à pesquisa científica e tecnológica com base no artigo $1^{\circ}$, parágrafo $2^{\circ}$ (BRASIL, 1990). Beneficiava a IES com a isenção do Imposto de Importação (II) e do Imposto sobre Produtos Industrializados (IPI), desde que fossem cumpridas as exigências do CNPq (Conselho Nacional de Desenvolvimento Científico e Tecnológico), bem como, contemplava as IES com quotas de importação predefinidas. Segundo E4, como estas cotas nem sempre eram utilizadas de acordo com que foram destinadas, muitas Instituições superestimavam valores a serem gastos com importações (com receio de faltar) e não as efetivavam ao término do exercício, causando desequilíbrio e impedindo que outras Instituições importassem por falta de quota. Em relação à existência de dificuldades na comprovação do benefício de isenção, os entrevistados E2 e E4, relataram que já tiveram problemas no passado quanto à comprovação perante a Receita Federal de sua Filantropia institucional.

Os entrevistados E1 e E2 concordam que a importação é vantajosa para a Instituição em relação a custos: "em relação ao mercado geral nacional a gente tem vantagem né, outros que forem fazer importação teriam um custo muito superior sem a isenção" (E1). E2 concorda afirmando "Assim, em questão de custo vale a pena porque nossa a carga tributária do Brasil é muito pesada, então do ponto de vista de custos é como estar num paraíso (risos)".

E a última pergunta da categoria mostrada no Quadro 11, finalizando as entrevistas foi: “Quais são as maiores dificuldades encontradas no processo de importação?”.

Quadro 11 Dificuldades do processo de importação

\begin{tabular}{|c|c|c|c|}
\hline E1 & E2 & E3 & E4 \\
\hline $\begin{array}{l}\text { "Maior dificuldade do } \\
\text { processo de importação é } \\
\text { se conseguir múltiplos } \\
\text { fornecedores para os } \\
\text { produtos que às vezes } \\
\text { são bem específicos e } \\
\text { com detalhamento } \\
\text { técnico". }\end{array}$ & $\begin{array}{l}\text { "O que mais impacta é a } \\
\text { diversidade de } \\
\text { equipamentos, mas como } \\
\text { uma IES a gente traz as } \\
\text { coisas que são muito } \\
\text { controladas } \\
\text { ANVISA [...]". }\end{array}$ & $\begin{array}{l}\text { "o processo como um } \\
\text { todo demora muito, de } \\
\text { quando chega a } \\
\text { solicitação até fazer todo } \\
\text { esse desembaraço e a } \\
\text { mercadoria chegar aqui". }\end{array}$ & $\begin{array}{l}\text { "Acredito que a maior } \\
\text { dificuldade é a } \\
\text { burocracia brasileira, por } \\
\text { mais que existam leis } \\
\text { que incentivem a } \\
\text { importação destinada ao } \\
\text { ensino, pesquisa } \\
\text { tecnologia". }\end{array}$ \\
\hline
\end{tabular}

Os entrevistados tiveram opiniões divergentes. Segundo E1 a maior dificuldade do processo de importação é a seleção de mais de um fornecedor para o mesmo produto, pois são importados produtos e/ou equipamentos específicos, gerando uma maior dificuldade na comparação de propostas, além de muitas vezes depender de uma análise externa das mesmas.

E2 considera que a diversidade de produtos importados pela IES, acaba sendo um ponto fraco no processo, onde por conta dessa diversidade há dificuldade no mapeamento do 
processo, ou precisa-se interagir com diferentes órgãos anuentes (MAPA; MRE; MDIC), que acaba onerando o processo como um todo. A percepção de E3 é condizente com o que se espera dos processos de importações, que demandam mais pessoas envolvidas e o tempo para recebimento da mercadoria é maior, comparando com compras do mercado nacional. Ressalva que normalmente as impressões das pessoas internas envolvidas no processo de importação, quando uma mercadoria importada chega a Instituição estudada, são diversos comentários, tais como: “[...] ainda bem que chegou, nossa que bom que chegou [...]”. Já E4 aponta que a burocracia brasileira que infelizmente ainda se torna um grande problema ao importar.

\subsection{PERCEPÇÕES DOS SOLICITANTES}

Para complementar a análise foram entrevistados dois solicitantes regulares (E5 e E6) de produtos e/ou contratações de serviços ao setor de compras, e que também solicitam mercadorias a serem importadas. A escolha desses dois colaboradores se deu através de sugestões dos entrevistados E1 e E2, pois são os maiores utilizadores dos serviços de compras internacionais, principalmente equipamentos importados para laboratórios de pesquisa e desenvolvimento.

A primeira pergunta foi referente à estrutura do setor: "Qual a tua percepção no que se refere ao setor de compras quanto à estrutura (tanto estrutura física quando estrutura de pessoas)?". Os dois entrevistados apontaram informações em comum quanto ao espaço físico e suas carências, e também quanto à reestruturação obtida no setor recentemente, já apontada anteriormente por E1, gestor da área.

Quadro 12 Percepção da estrutura do setor de compras

\begin{tabular}{|c|c|}
\hline E5 & E6 \\
\hline $\begin{array}{l}\text { "Eu acho que as instalações são relativamente boas, } \\
\text { poderiam estar melhor climatizadas né [...] quanto ao } \\
\text { espaço físico, a área parece boa acho que tem, cada } \\
\text { funcionário parece ter o seu espaço, seu nicho de } \\
\text { trabalho bem organizado, mesas individuais, } \\
\text { computadores e telefone. Em termos de pessoas e da } \\
\text { estrutura, acho que evoluiu bastante [...]". }\end{array}$ & $\begin{array}{l}\text { "A estrutura de pessoal sob a coordenação anterior } \\
\text { apresentava número de pessoas inferior ao ideal para } \\
\text { o atendimento às necessidades hoje é adequado, } \\
\text { entretanto não apresenta ligação interna com os } \\
\text { outros setores administrativos da Instituição.[...] a } \\
\text { área de reuniões com os fornecedores também } \\
\text { poderia ser ampliada." }\end{array}$ \\
\hline
\end{tabular}

A pergunta seguinte também se referiu às percepções dos respondentes quanto ao atendimento de suas demanda e funcionamento do setor: "Qual a tua percepção ao que se 
refere ao setor de compras quanto os seus processos/funcionamento?”. O Quadro 13 apresenta um resumo das respostas dos entrevistados.

Quadro 13 Percepção de atendimento do setor de compras

\begin{tabular}{|c|c|}
\hline E5 & E6 \\
\hline $\begin{array}{l}\text { "Não vejo nenhum déficit aparente com compras né. } \\
\text { Os solicitantes não têm percepção da complexidade, } \\
\text { então se sofre muito com isso, pela falta de } \\
\text { conhecimento de quem solicita [...] a maioria não } \\
\text { entende dos processos administrativos [...] e acho } \\
\text { que esses processos ganham cada vez mais } \\
\text { transparência, através do sistema de compras [...] } \\
\text { diminui muito essa percepção de que compras é } \\
\text { lento, não compraram a melhor compra [...]". }\end{array}$ & $\begin{array}{l}\text { "Houve uma grande melhoria nos processo de } \\
\text { aquisição de materiais ou serviços a partir da } \\
\text { implantação do novo sistema de compras. A } \\
\text { principal vantagem é permitir acompanhar em que } \\
\text { etapa cada solicitação de aquisição encontra-se. } \\
\text { Ainda o serviço interno de mensagens permitiu uma } \\
\text { maior troca de informações entre compradores e } \\
\text { solicitantes, mantendo o registro das comunicações } \\
\text { disponível a todos interessados [...]". }\end{array}$ \\
\hline
\end{tabular}

Para E5 e E6 o atendimento de suas demandas são satisfatórias e os dois comentam a diferença percebida por eles após implantação de um sistema único de compras. As demandas virtuais incluídas no sistema facilitam o acompanhamento das mesmas e também dá a transparência aos processos. O gestor do setor (E1), já havia relatado que o sistema proporciona agilidade no recebimento e atendimento das demandas dos outros setores comparando com o processo anterior, que não era totalmente automatizado, assim como E2 e E3, que em suas entrevistas afirmaram ter maior agilidade no atendimento dessas demandas com esse novo sistema e também foi ressaltada por E1, a transparência de informações proporcionada. Todos estes pontos também são percebidos pelos solicitantes entrevistados.

Os entrevistados E5 e E6 também sugeriram melhorias nos processos de compras. E5 sugeriu que o setor tivesse uma ferramenta gerencial de pesquisa, para que o gestor, assim como os compradores, possa receber avaliações dos solicitantes, e que estas avaliações tornem-se um indicativo para o setor

A última pergunta realizada se refere às percepções quanto aos processos de importação: “Qual é a tua percepção do setor de compras quanto às importações?”.

Pode-se notar pelo Quadro 14 que existem algumas deficiências nos processos de importações. Um dos pontos em comum citados por E5 e E6 é que o processo de importação não está modernizado, ainda está sendo executado via formulário em papel. E5 e E6 classificam o processo de importação como lento e demorado por si só, e caso utilizassem o processo de aprovações pelo novo sistema de compras ter-se-ia ganho de tempo.

Outro ponto negativo levantado em comum entre os respondentes é a troca recente da empresa de consultoria e despacho aduaneiro realizada pelo setor de compras. Os dois relatam 
que a empresa, se comparada com a anterior, não possui experiência nas importações diversificadas da Universidade. A falta de experiência acaba sobrecarregando os compradores responsáveis pelas importações ou até mesmo o pesquisador, que precisa auxiliar na classificação de NCM, já que o despachante não conhece os produtos importados.

Quadro 14 Percepção dos processos de importação

\begin{tabular}{|c|c|}
\hline E5 & E6 \\
\hline $\begin{array}{l}\text { “... ] é uma tarefa difícil de chegar a pontos em } \\
\text { comuns desde a especificação do equipamento, o que } \\
\text { o pesquisador pediu e o que o comprador vai poder } \\
\text { encontrar [...] como aprendizagem pra gente não } \\
\text { cometer de novo é preciso registrar historicamente o } \\
\text { que vem acontecendo, a gente tem que ter indicador } \\
{[\ldots] \text { nós estamos educando esse novo importador a }} \\
\text { entender melhor as nossas mudanças [...] no fim } \\
\text { trabalhos que era pra ser feitos pelo aduaneiro volta } \\
\text { pra mesa do comprador ou do pesquisador }\end{array}$ & $\begin{array}{l}\text { “[...] as importações ainda utilizam a Solicitação de } \\
\text { Compras em papel [...] a obtenção das aprovações } \\
\text { para a importação de produtos ou serviços pode levar } \\
\text { vários dias [...] foi substituída a empresa terceirizada } \\
\text { responsável pela confecção de documentação e } \\
\text { liberação alfandegária [...] a nova empresa passou a } \\
\text { solicitar uma quantidade maior de documentos do } \\
\text { que a empresa anterior e apresentava pouca } \\
\text { experiência na liberação de cargas sujeitas ao } \\
\text { controle da ANVISA [...]". }\end{array}$ \\
\hline
\end{tabular}

O entrevistado E6 relata algumas de suas experiências negativas quanto à nova empresa contratada prestadora de serviços de consultoria e despacho aduaneiro "a minha percepção é de que a nova empresa passou a solicitar uma quantidade maior de documentos do que a empresa anterior e pouca experiência na liberação de cargas sujeitas ao controle da ANVISA"

Percebe-se nos dois relatos a insatisfação por parte de E5 e E6 quanto à empresa prestadora de serviços de consultoria e despacho aduaneiro, por conta da inexperiência com as importações de IES, causando uma demora maior nos processos de importação.

O entrevistado E5 reforça algumas percepções respondidas na questão anterior, onde acha fundamental poder dar o seu feedback em todos os processos, pois acredita, e pode-se dizer que fortemente, já que mencionou várias vezes na entrevista, que a diminuição de erros ou aumento de acertos podem ser facilitados com a opiniões das áreas demandantes, possibilitando o comprador um maior entendimento de sua compra, seja positivamente ou negativamente. E também reforça que ele no papel de pesquisador, gostaria de colaborar mais com as compras de seus materiais.

\section{CONSIDERAÇÕES FINAIS}

O presente estudo identificou as características do departamento de compras e dos processos de importação de uma IES Comunitária captando as percepções dos colaboradores 
de suas dificuldades e motivações, considerando pontos que são característicos do universo de uma IES comunitária se comparado as outras IES ou mesmo a empresas tradicionais. Destacase a importância de uma apropriada gestão dos processos de compras e de importação como meio facilitador para impulsionar a pesquisa científica e tecnológica.

Os resultados mostram que o setor está buscando um novo alinhamento entre o estratégico e o operacional, ampliando o uso do manual de compras e tendo mais do que uma pessoa em condições de realizar uma mesma função. Os objetivos principais do setor são a compra econômica ou o menor preço e atender no prazo. A qualidade dos produtos e serviços foi mencionada, mas é fundamental que esteja alinhada com preço e prazo. Um objetivo exclusivo da IES é que o processo seja claro e auditável, pois existem inúmeros projetos financiados por fontes externas que exigem licitações e outros aspectos legais.

Está presente o conflito entre a modernização e melhora de controle através do sistema e o antigo modo manual e pessoalizado, que ainda faz parte do dia a dia do setor. As áreas de extensão e de pós-graduação devido à complexidade e irregularidade das demandas, ainda se utilizam do processo antigo não informatizado.

As maiores dificuldades do setor são os aspectos externos. As descrições dos itens são muito genéricas e o comprador por diversas vezes precisa retornar a demanda para o solicitante até encontrar uma descrição mais detalhada e objetiva fruto da diversidade e irregularidade dos itens comprados. Outra dificuldade é o fato de que os solicitantes não conhecem os procedimentos burocráticos e legais da instituição e atribuem à demora ou ausência de itens ou serviços a incapacidade do setor de compras.

Já a maior dificuldade no ambiente interno é o fato de que os compradores não dominam todas as opções e facilidades que o sistema informatizado proporciona. O sistema tem um ano e meio de implantação com diferentes níveis de apropriação dessas funções e opções. Além disso, há a consciência de que se cada comprador conduzir os processos a sua maneira sem obedecer a uma dinâmica comum definida pelo manual de compras resultará em processos ruins impactando negativamente as expectativas dos solicitantes.

No que se refere à atividade de importação fica claro o fato de que não são corriqueiras na IES, embora quando existam sejam de alto valor, únicas e com muitos aspectos peculiares. No cotidiano não são buscados fornecedores internacionais, apenas quando são exigidos pelos solicitantes. A maior demanda por itens internacionais provem da pesquisa ou extensão e conta com o benefício da isenção de impostos por ser uma Instituição de ensino filantrópica. Para os tramites internacionais a IES se utiliza de um escritório 
despachante, mas tem condições de realizá-lo todo dentro da instituição caso aumente a demanda, é visível o fato de que o escritório tem dificuldades com processos para instituições de ensino em especial comunitárias. Como a área de importação divide espaço com as demais não tendo uma estrutura específica, conclui-se que o assunto não está tendo prioridade na IES.

Ao fim e ao cabo, esse estudo é um modelo dos desafios que os profissionais de compras podem encontrar nas IES Comunitárias e também como guia para estas Instituições que desejam melhorar, atuando sobre as principais dificuldades encontradas nos processos relacionados às suas compras e importações.

\subsection{LIMITAÇÕES PRÁTICAS E SUGESTÕES DE ESTUDOS FUTUROS}

Apesar da relevância do assunto abordado, algumas limitações foram percebidas. Embora a proposta tenha trazido um olhar diferenciado com uma síntese de boas práticas e recursos utilizados, referem-se à IES estudada e não pode ser generalizado, mas sim servir como base. A localização de fontes bibliográficas específicas na área de compras das IES Comunitárias dificultou a pesquisa. Igualmente limitante foi a escolha dos respondentes para a pesquisa, uma vez que todos os entrevistados foram selecionados por conveniência, o que pode resultar em algum viés nas avaliações.

Como sugestões de futuros estudos, a pesquisa aponta algumas direções. A possibilidade da construção de um modelo padrão do processo de compras tanto para aquisições de bens e serviços nacionais como internacionais, tendo-se por base a análise das percepções dos colaboradores do caso de estudo. Sugere-se também verificar esses processos em outras IES Comunitárias, para que se possam perceber outros aspectos além dos já apresentados nesse estudo, para serem aplicados como instrumento de pesquisa e/ou apoio de outras Instituições.

\section{REFERÊNCIAS}

ABRUC - Associação Brasileira das Universidades Comunitárias. Disponível em: < http://www.abruc.org.br/ >. Acesso em 29 março. 2016.

AMMER, Deans S. Administração de material. Tradução Claudio José Fernandes de Azevedo. 3. ed. Rio de Janeiro: LTC, 1979.

ARAÚJO, Jorge Sequeira de. Administração de materiais. 5.ed. São Paulo: Atlas, 1978.

ARNOLD, J R Tony. Administração de materiais: uma introdução. Tradução Celso Rimoli, Lenita R. Esteves. 1.ed. São Paulo: Atlas, 1999. 
BAILY, Peter; FARMER, David. Compras: princípios e administração. 1.ed. São Paulo: Atlas, 2000.BARDIN, L. Análise de Conteúdo. Tradução Luís Antero Reto e Augusto Pinheiro. 3. ed. Lisboa : Edições 70, 2004.

BRASIL - Constituição da República Federativa do Brasil: de 5 de outubro de 1988. Disponível em: < http://www.planalto.gov.br/ccivil_03/constituicao/constituicao.htm $>$. Acesso em 26 abril 2016.

BRASIL. Lei n. 8.010, de 29 de março de 1990. Dispõe sobre importações de bens destinados à pesquisa científica. In SENADO FEDERAL. Legislação Republicana Brasileira. Brasília, 1999. Disponível em: < https://www.planalto.gov.br/ccivil 03/leis/1989 1994/L8010.htm> Acesso em: 20 outubro 2016.

BRASIL. Lei n. 9.394, de 20 de dezembro de 1996. Estabelece as diretrizes e bases da educação nacional. In SENADO FEDERAL. Legislação Republicana Brasileira. Brasília, 1996. Disponível em: < https://www.planalto.gov.br/ccivil_03/leis/L9394.htm > . Acesso em 26 abril 2016.

BRASIL. Lei n. 12.881, de 12 de novembro de 2013. Dispõe sobre a definição, qualificação, prerrogativas e finalidades das Instituições Comunitárias de Educação Superior. In SENADO FEDERAL. Legislação Republicana Brasileira. Brasília, 2013. Disponível em: < http://www.planalto.gov.br/ccivil 03/ Ato2011-2014/2013/Lei/L12881.htm >. Acesso em: 29 abril 2016.

COMUNG - Consórcio das Universidades Comunitárias Gaúchas. Disponível em: < https://www.comung.org.br/ >. Acesso em: 27 maio 2016.

DIAS, Marco Aurélio Pereira. Administração de materiais: princípios, conceitos e gestão. 6.ed. São Paulo: Atlas, 2011.

DIAS, Mário; COSTA, Roberto Figueiredo. Manual do comprador: conceitos, técnicas e práticas indispensáveis em um departamento de compras. 5.ed. São Paulo: Saraiva, 2012.

GIL, A. C. Métodos e técnicas de pesquisa social. 6. ed. São Paulo: Atlas,2008.

IBGE - Instituto Brasileiro de Geografia e Estatística. Projeção da população do Brasil e das Unidades da Federação. Disponível em: < http://www.ibge.gov.br/home/ > Acesso em: 22 abril 2016.

INEP - Instituto Nacional de Estudos e Pesquisas Educacionais Anísio Teixeira. Censo da Educação Superior 2013. Disponível em: <

http://download.inep.gov.br/download/superior/censo/2013/resumo tecnico_censo_educacao superior_2013.pdf > Acesso em: 22 abril 2016.

KÖCHE, J. C. Fundamentos de metodologia científica: a teoria da ciência e iniciação à pesquisa. 24 ed. Petrópolis, RJ: Vozes, 2007.

MAPA, MRE, MDIC - Guia de Comércio Exterior e Investimento. Disponível em: < http://www.investexportbrasil.gov.br/ >. Acesso em: 10 maio 2016. 
MARTINS, C. B. O ensino superior no Brasil: o setor privado. Revista Brasileira de Ciências Sociais. São Paulo, v.17, n.48. Fevereiro, 2012. Disponível em: < http://dx.doi.org/10.1590/S0102-69092002000100012 >. Acesso em 18 abril 2016.

MALHOTRA, N. K. Pesquisa de marketing: uma orientação aplicada. 3. ed.Porto Alegre: Bookman, 2001.

MEC - Ministério da Educação. Disponível em: < http://emec.mec.gov.br/emec/educacaosuperior/ies > Acesso em: 24 abril 2016.

RASMUSSEN, E., MOSEY, S., WRIGHT, M. The influence of university departments on the evolution of entrepreneurial competencies in spin-off ventures. Research Policy, vol. 43, n. 1, p.92-106. doi:10.1016/j, 2014.

SCHMIDT, J. P. - Instituições Comunitárias: instituições públicas não-estatais. 1.ed. Santa Cruz do Sul, RS: EDUNISC, 2009.

SIEWERDT, M. J. Público, comunitário, privado? O dilema das IES do sistema

ACAFE/SC. XXV Simpósio Brasileiro de Política e Administração da Educação. Niterói, RJ: ANPAE; São Paulo: PUCSP/FACED/PPGE, 2011. Disponível em: < http://www.anpae.org.br/simposio2011/cdrom2011/PDFs/trabalhosCompletos/comunicacoes

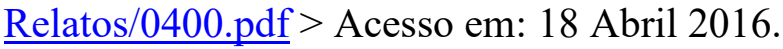

SLACK, Nigel et al. Administração da Produção. $1^{\circ}$ ed. São Paulo: Atlas, 1997.

UCS - Universidade de Caxias do Sul. Disponível em: < http://www.ucs.br/site/pesquisainovacao-e-desenvolvimento-tecnologico/ >. Acesso em: 19 abril 2016.

VANNUCCHI, A. A universidade comunitária: o que é, como se faz. 3.ed. São Paulo: Loyola, 2011.

YIN, R. K. Estudo de caso: planejamento e métodos. 4. ed. Porto Alegre: Bookman, 2010. 